\title{
Benefits of natural dietary trans fatty acids towards inflammation, obesity and type 2 diabetes: defining the n-7 trans fatty acid family ${ }^{\text {th }}$
}

\author{
Etienne Guillocheau ${ }^{1,2}$, Philippe Legrand ${ }^{1}$ and Vincent Rioux ${ }^{1, *, a}$ \\ ${ }^{1}$ Laboratory of Biochemistry and Human health, Agrocampus-Ouest, Rennes, France \\ ${ }^{2}$ French Dairy Interbranch Organization (CNIEL), Technical and Scientific Department, Paris, France
}

Received 9 July 2019 - Accepted 22 October 2019

\begin{abstract}
Natural trans fatty acids are trans fatty acids that naturally occur in ruminant-derived foods: milk (derived from cow, ewe, goat), dairy products (yoghurt, cheese) and ruminant meat (beef, lamb). Because natural trans fatty acids are part of the trans fatty acid family, they have been compared for decades to their industrial counterparts on a cardiovascular outcome's basis. At current dietary intakes, it is now well recognized that natural trans fatty acids are neutral towards cardiovascular health. Still, the negative connotation remains. It is usually taken for granted in the scientific community that natural trans fatty acids have no known physiological function and therefore no particular nutritional interest. This prevailing view has totally hidden several studies, which pointed out unsuspected benefits of natural trans fatty acids on inflammation, type 2 diabetes and obesity. Some supplementation studies dealt with pure trans-vaccenic acid (trans-C18:1 n-7) and pure rumenic acid (cis-9, trans-11 C18:2), but remained somewhat aside as they were carried out on rodents. However, recent epidemiological data reached considerable impact, highlighting a protective effect of trans-palmitoleic acid (trans-C16:1 n-7) towards the risk of type 2 diabetes. Bearing in mind that natural trans fatty acids do not just consist of rumenic acid, this review is the opportunity to sum up scientific knowledge about each of these three fatty acids. We shall therefore, review their occurrence in foods, and their physiological impacts. An overlooked aspect of natural trans fatty acids is that they are metabolically connected. The second aim of this review is to underline these metabolic connections. In fact, combining physiological impacts and metabolic pathways unravel shared mechanisms of action of trans-palmitoleic, trans-vaccenic and rumenic acids, that might be explained by their common n-7 trans double bond.
\end{abstract}

Keywords: dairy products / metabolism / ruminant meat / trans-palmitoleic acid / trans-vaccenic acid / rumenic acid

Résumé - Bénéfices physiologiques des acides gras trans naturels alimentaires sur l'inflammation, l'obésité et le diabète de type 2 : définition de la famille des acides gras $\mathbf{n}-\mathbf{7}$ trans. Les « acides gras trans naturels » sont des acides gras trans que l'on trouve naturellement dans les aliments issus des mammifères ruminants : le lait (de vache, brebis, chèvre), les produits laitiers (yaourt, fromage) et la viande (bœuf, agneau). Comme ils appartiennent à la famille des acides gras trans, les trans naturels ont été comparés pendant des décennies à leurs homologues industriels, sur fond de risques cardiovasculaires. Il est désormais bien démontré qu'aux apports nutritionnels actuels, les acides gras trans naturels sont neutres sur la santé cardiovasculaire. Cependant, une connotation négative subsiste. La communauté scientifique considère encore bien souvent que les acides gras trans naturels ne sont associés à aucune fonction physiologique bien décrite et que leur intérêt nutritionnel est donc inexistant. Cette perception s'oppose aux résultats de

\footnotetext{
${ }^{2}$ Contribution to the Topical Issue "Lipids and health / Lipides et santé"

*Correspondence: vincent .rioux@agrocampus-ouest.fr

a Present address: Laboratory of Biochemistry and Human Nutrition, Agrocampus-Ouest, 65 rue de Saint-Brieuc, 35042 Rennes Cedex, France
} 
plusieurs études démontrant des bénéfices physiologiques insoupçonnés des acides gras trans naturels sur l'inflammation, le diabète de type 2 et l'obésité. Ces résultats ont d'abord été obtenus par des études nutritionnelles de supplémentation en acide ruménique (C18:2 cis-9, trans-11) ou en acide trans-vaccénique (C18:1 n-7 trans) purs sur le modèle rongeur. Ces résultats ont aussi été complétés par de nombreuses données épidémiologiques récentes, qui associent les plus forts taux circulants d'acide trans-palmitoléique (C16:1 n-7 trans), marqueur de consommation de produits alimentaires issus de ruminants, à un moindre risque de diabète de type 2 . Il s'agit ici de synthétiser les connaissances scientifiques obtenues sur ces trois acides gras trans naturels alimentaires, l'acide ruménique, l'acide trans-vaccénique et l'acide transpalmitoléique. Dans cette revue, nous détaillerons donc d'abord leur présence quantitative dans les aliments, ainsi que leurs impacts physiologiques démontrés. Nous soulignerons ensuite les liens métaboliques existants entre ces trois acides gras. En combinant les connaissances sur les impacts nutritionnels et les données métaboliques, il apparaît que les mécanismes similaires d'action de ces trois acides gras pourraient être expliqués par leur double liaison n-7 trans commune.

Mots clés : acide trans-palmitoléique / acide trans-vaccénique / acide ruménique / produits laitiers / métabolisme / viandes de ruminants

\section{What are natural trans fatty acids?}

Natural trans fatty acids are specific fatty acids with at least one trans double bond. They are naturally occurring in ruminant-derived foods (milk and ruminant meat). Natural trans fatty acids typically arise from bacterial activity during the ruminal biohydrogenation of dietary linoleic acid (cis-9, cis-12 C18:2, LA) and $\alpha$-linolenic acid (cis-9, cis-12, cis-15 C18:3, ALA). Since Eukaryotes are unable to synthesize fatty acids with trans double bonds, natural trans fatty acids are therefore quantitatively minor and unusual fatty acids, but still biological fatty acids.

Being mainly derived from $\mathrm{C} 18$ fatty acids, natural trans fatty acids mainly consist of $\mathrm{C} 18$ fatty acids as well. The most famous one is rumenic acid (cis-9, trans-11 C18:2, RMA), which is derived partly from dietary LA ruminal biohydrogenation. Another important natural trans fatty acid is trans-vaccenic acid (trans-C18:1 n-7, TVA) which arises both from dietary LA and ALA and can be synthesized from RMA. Finally, trans-palmitoleic (trans-C16:1 n-7, TPA) might stem from the retro-conversion of TVA that occur in the key tissues (e.g., muscle, liver and mammary gland) of ruminant species.

\section{Trans-palmitoleic acid (TPA)}

Trans-palmitoleic acid (TPA) is a hexadecenoic acid having a trans double bond located in the 9th position ( $\Delta$-nomenclature, trans-9 $\mathrm{C16:1)}$ or in the $\mathrm{n}$-7th position ( $\Omega$-nomenclature, trans-C16:1 n-7) (Fig. 1A). Thus, TPA is a trans-monounsaturated fatty acid, and a trans fatty acid according to several reglementary definitions (CODEX, 1985; FDA, 2003; EFSA, 2004; AFSSA, 2005). One may also find in the literature TPA denoted as "palmitelaidic acid", with reference to elaidic acid (trans-9 C18:1; two-carbons longer than TPA). However, because elaidic acid is not a natural trans fatty acid (Wolff et al., 2000), this term appears inadequate.

The minor but reproducible presence of TPA in dairy products is well-documented. Destaillats et al. reported a mean TPA content of $0.05,0.04$ and $0.08 \%$ of total fatty acids in milk of cow, ewe and goat respectively (Destaillats et al., 2000). In line with these quantitative data, epidemiological studies found dairy product consumption to be positively correlated to circulating levels of TPA in humans (Sun et al., 2007; Micha et al., 2010; de Oliveira Otto et al., 2013; Da Silva et al., 2014; Nestel et al., 2014; Yakoob et al., 2016; Pranger et al., 2019). Despite doubts about the presence of TPA in partially hydrogenated oils (Santaren et al., 2014), our research group recently demonstrated that dairy products and ruminant meat are the unique contributors of TPA intake in France, relying on accurate analytical data (Guillocheau et al., 2018). In other words, circulating TPA in humans can be considered as a biomarker of ruminant fat consumption at least in countries where partially hydrogenated oils are not used anymore.

Most of the available data regarding the promising health effects of TPA comes from prospective epidemiological studies dealing with the risk of type 2 diabetes. In the CHS cohort, Mozaffarian et al. found a significantly reduced risk of type 2 diabetes in the highest quintile of circulating TPA (Mozaffarian et al., 2010). Consistently, an inverse relationship was found between circulating levels of TPA and type 2 diabetes risk in the MESA cohort (Mozaffarian et al., 2013). In both HPFS and NHS cohorts, high circulating levels of TPA were again associated with significantly lowered type 2 diabetes risk (Yakoob et al., 2016). In addition of these prospective studies, two metaanalyses found a significantly reduced risk of type 2 diabetes with the extreme quintiles of circulating TPA (de Souza et al., 2015; Imamura et al., 2018). In addition, some of these epidemiological studies measured circulating metabolic parameters. Importantly, both the CHS and the MESA cohorts pointed out significantly reduced levels of fasting insulinemia across quintiles of circulating TPA, contributing to a better insulinsensitivity as measured by the HOMA-IR index (Mozaffarian et al., 2010, 2013). These two prospective studies suggest a favourable impact on circulating insulinemia at the very early stages of metabolic dysfunctions, thus preventing from the settlement of the latter. One may suppose insulin secretion and/or insulin clearance to be targeted by dietary TPA.

Several studies carried out on cell models investigated the physiological impacts of TPA. In endothelial (HUVEC) and hepatic (HepG2) cells, TPA reduced TNF- $\alpha$ induced inflammatory expression (Da Silva et al., 2017). Another interesting study highlighted improved pancreatic $\beta$-cell function (INS1 cells) following incubation with TPA, by means of higher PPAR- $\gamma$ expression (Kraft et al., 2015). This latter finding closely parallels the epidemiological studies that assumed an improved $\beta$-cell function associated with high levels of circulating TPA. 
A

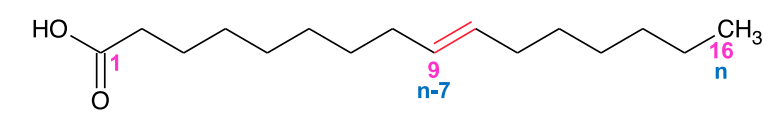

B
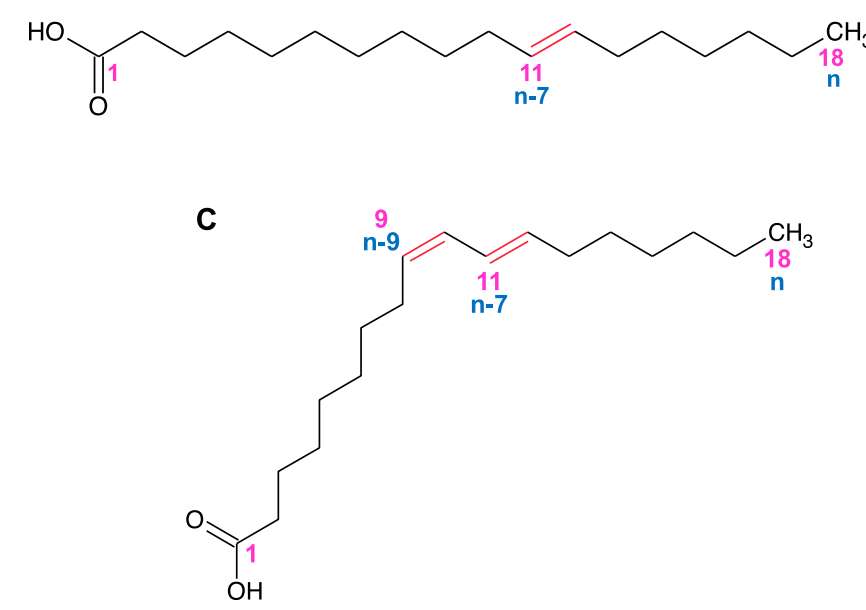

Fig. 1. Structure of (A) trans-palmitoleic acid, (B) trans-vaccenic acid and (C) rumenic acid. The location of the double bond relies on either the $\Delta$-nomenclature (pink), or the $\Omega$-nomenclature (blue).

Of note, a TPA-supplementation study carried on $\mathrm{ApoE}^{-/-}$ male mice was recently published (Cimen et al., 2019). Given the chosen rodent model, this study dealt more about atherosclerosis rather than type 2 diabetes, but still deserves some attention. Indeed, TPA was found to be neutral as regards to the progression of atherosclerosis. Besides, TPA did not impact the ratio between total cholesterol and HDL-cholesterol in plasma, suggesting a neutral effect of TPA on biomarkers of cardiovascular diseases.

So far, to the best of our knowledge, there is no published supplementation study involving TPA to confirm a favourable impact towards insulin sensitivity and pancreatic $\beta$-cell function. This is due to the very low availability of pure TPA in enough amounts, at least to carry out a supplementation study on rodent models. However, it should be underlined that the treatment of insulin-resistance by TPA was patented in 2014 by Dariush Mozaffarian and his research group (Patent No. Patent US 8,889,739 B2, 2014), testifying of the probable interesting health benefits of TPA.

\section{Trans-vaccenic acid (TVA)}

Trans-vaccenic acid (TVA) is an octadecenoic acid having a trans double bond located in the 11th position ( $\Delta$-nomenclature, trans-11 C18:1) or in the $\mathrm{n}-7$ th position ( $\Omega$-nomenclature, trans-C18:1 n-7) (Fig. 1B). Therefore, TVA is a transmonounsaturated fatty acid and a trans fatty acid (CODEX, 1985; EFSA, 2004; FDA, 2003; AFSSA, 2005), just like TPA. Formally speaking, vaccenic acid refers to what we call here trans vaccenic acid. To avoid any confusion with the cis isomer (cis-11 C18:1, or cis-C18:1 n-7) which is sometimes called vaccenic acid as well, we shall use here the term trans vaccenic acid (TVA).
Consistent accurate data reported the presence of TVA in dairy products available in supermarkets. TVA content in such products is comprised between 1.5 and $4 \%$ of total fatty acids (Precht and Molkentin, 1996, 2000b; Kuhnt et al., 2011). Ruminant meat also contains TVA which accounts for between 1 and 3\% of total fatty acids (Aldai et al., 2009, 2010; BravoLamas et al., 2016). Even if TVA is often found in partially hydrogenated oils (Precht and Molkentin, 2000a; Wolff et al., 2000), our research group recently provided formal evidence of the exclusive contribution of ruminant-derived foods to TVA intakes in France (Guillocheau et al., 2018). Just like circulating TPA, circulating TVA in humans can, therefore, be considered as a biomarker of ruminant fat intake at least in countries where partially hydrogenated oils are not used anymore.

Like TPA, there is a strong lack of commercial availability of pure TVA. Fortunately, the main difference is that self-chemical synthesis and purification of TVA are already described (Duffy et al., 2006; Mouloungui and Candy, 2009; Gebauer et al., 2011), making TVA-supplementation studies feasible. Most of these studies were carried out on rodent models. In JCR-LA:cp rats which are a rodent model of type 2 diabetes and dyslipidemia, a TVA-enriched diet led to significantly reduced levels of TAG (Wang et al., 2008), reduced NAFLD and decreased hepatic expression of FAS and ACC (Wang et al., 2008; Jacome-Sosa et al., 2014). Furthermore, a significant decrease in adipose tissue weight and adipocyte size was noticed in both JCR-LA:cp (JacomeSosa et al., 2014) and Zucker rats (Mohankumar et al., 2013) fed with pure TVA. This latter impact might be due to the ability for TVA to be a natural ligand of PPAR- $\alpha$ and PPAR- $\gamma$ (Wang et al., 2012). Finally, dietary TVA exerted antiinflammatory effects on JCR-LA:cp splenocytes (Blewett et al., 2009). Taken together, these studies highlight interesting features of dietary TVA towards insulin resistance, dyslipidemia and systemic inflammation. So far, no study was carried out on healthy rodents challenged with a Western-country diet while supplemented with TVA to investigate the preventive impact of dietary TVA towards type 2 diabetes.

To our knowledge, only one clinical study investigated the effect of pure TVA on metabolic parameters related to type 2 diabetes (Gebauer et al., 2011, 2015). In this study, healthy volunteers fed with pure TVA had no change as regards to glycemia, insulinemia and insulin resistance compared with the control group. These results may suggest a neutral effect of dietary TVA, but it is worth underlining that volunteers were healthy and received a normal diet.

Finally, very recent epidemiological work cross-sectionally associated circulating levels of TVA in humans with lower adiposity, diabetes risk and systemic inflammation (Pranger et al., 2019). To the best of our knowledge, this is the only epidemiological study focusing on the physiological impacts of dietary TVA.

\section{Rumenic acid (RMA)}

Rumenic acid (RMA) is an octadecadienoic acid having one trans double bond located in the 11th position ( $\Delta$-nomenclature), or $\mathrm{n}$-7th position like TPA and TVA 
( $\Omega$-nomenclature). In addition, RMA has a cis double bond located in the 9 th position ( $\Delta$-nomenclature), or $n-9$ th position ( $\Omega$-nomenclature). Thus, RMA (cis-9, trans-11 C18:2 using the $\Delta$-nomenclature) has a conjugated-double bond system (Fig. 1C) and belongs to the well-known conjugated-linoleic acid (CLA) family. Whether RMA is a trans fatty acid is a much-debated issue: while the EFSA and the ANSES consider RMA as a CLA and as a trans fatty acid (EFSA, 2004; AFSSA, 2005), the FDA and the Codex Alimentarius (CODEX, 1985; FDA, 2003) consider RMA as a CLA and not as a trans fatty acid. Such a distinction between CLA isomers and trans fatty acids is based on the widespread idea that all CLA isomers should exert health benefits, contrary to trans fatty acids (e.g., TPA and TVA). In this review, we shall agree with the EFSA and the ANSES considering RMA as a trans fatty acid naturally occurring in ruminant-derived foods.

Like for TPA and TVA, the presence of RMA in dairy products available at retail is well-documented. RMA accounted for approx. $0.5 \%$ of the total fatty acids in Canadian dairy products (Sehat et al., 1998; Mendis et al., 2008). Higher variability is encountered in ruminant meat. In Canadian beef, RMA levels were between 0.26 and $0.41 \%$ of total fatty acids (Aldai et al., 2009, 2010), while Spanish lamb samples displayed an RMA content up to $0.7 \%$ of total fatty acids (Bravo-Lamas et al., 2016). Thus, RMA is a fatty acid specific to ruminant fat.

To the best of our knowledge, there are no epidemiological studies focusing on physiological effects of RMA. As regards to supplementation studies, the situation is the same as for TPA and TVA, that is a lack of availability of pure RMA in elevated amounts despite some protocols describing how to get enough amounts of pure RMA (Duffy et al., 2006). It is worth underlining how crucial the purity issue is in the case of RMA. Indeed, numerous randomized control trials were performed using CLA supplements that actually consist of a mix of CLA isomers, as reviewed by Tremblay and Rudkowska (2017). In particular, the trans-10, cis-12 C18:2 fatty acid (i.e., a CLA isomer) is usually encountered in these dietary supplements. However, all CLA isomers are not equivalent to human health, particularly when it comes to diabetes and NAFLD (Clément et al., 2002; Roche et al., 2002). Thus, all these clinical studies are not suitable for assessing the physiological impacts of dietary RMA and thus shall not be reviewed here.

Just like TVA, most supplementation studies involving pure RMA were carried out on rodents. Roche et al. found a significant decrease in SREBP-1c expression in the liver of $\mathrm{Ob}$ / $O b$ mice fed pure RMA, followed by a significant decrease in circulating NEFA and TAG (Roche et al., 2002). In strong agreement with these findings, dietary RMA prevented NAFLD in Wistar rats fed a high-fat diet (Gaita et al., 2014). It was proposed that such effects of dietary RMA might be mediated by favourable inflammatory impacts in white adipose tissue of $\mathrm{Ob} / \mathrm{Ob}$ mice (Moloney et al., 2007). In fact, it was very soon proposed that dietary RMA acted as a ligand of PPAR- $\alpha$ and PPAR- $\gamma$ (Moya-Camarena et al., 1999). Such mechanism is consistent with the improvement of type 2 diabetes and NAFLD in studies involving rodents. In strong agreement with this hypothesis, other studies carried out on cell models (Yang and Cook, 2003; Jaudszus et al., 2005; Reynolds et al., 2008; Loscher et al., 2014), rodents (Jaudszus et al., 2008) and humans (Turpeinen et al., 2008) also pointed out anti-inflammatory impacts of dietary RMA that may involve PPAR- $\gamma$. Overall, interesting health benefits of dietary RMA are highlighted towards systemic inflammation, NAFLD and dyslipidemia.

The only clinical study that investigated the physiological impacts of dietary TVA also focused on dietary RMA. Relying on another group fed with pure RMA, Gebauer et al. did not show any effect of dietary RMA on glycemia, insulinemia and insulin-resistance (Gebauer et al., 2011, 2015). Again, it should be quoted that the study was carried out on healthy volunteers fed a normal diet.

\section{Metabolic pathways: bridging the gap between TPA, TVA and RMA, and derivatives}

TPA, TVA and RMA all arise from ruminal biohydrogenation of dietary fatty acids. Some metabolic connections between these fatty acids are already described in ruminants but remain somewhat overlooked when it comes to human nutrition. Despite not being able to synthesize trans fatty acids, humans are however able to metabolize dietary natural trans fatty acids by reactions of elongation, $\beta$-oxidation and desaturation (Fig. 2).

To the best of our knowledge, only our research group deeply investigated the metabolism of TPA in fresh cultured rat hepatocytes, relying on $\left[1-{ }^{13} \mathrm{C}\right]-\mathrm{TPA}$ (Guillocheau et al., unpublished results). On the one hand, an unlabeled trans C14:1 compound was detected, presumably the trans-7 C14:1 testifying of the ability of TPA to undergo peroxisomal $\beta$-oxidation (Fig. 2). On the other hand, ${ }^{13} \mathrm{C}$-labelled TVA was detected, undoubtedly arising from an elongation step. Importantly, we did not detect any trans C16:2 compound that would highlight a desaturation step involving TPA. Thus, TPA can only undergo elongation and peroxisomal/mitochondrial $\beta$-oxidation reactions.

Perhaps the main reaction that dietary TVA undergoes is its $\Delta$ 9-desaturation yielding RMA (Fig. 2), a well-described step in both rodents (Santora et al., 2000; Gruffat et al., 2005; Kraft et al., 2006) and humans (Turpeinen et al., 2002; Kuhnt et al., 2006; Mosley et al., 2006). Our research group also demonstrated the $\Delta 13$-desaturation of TVA to obtain a conjugated trans-11, cis-13 C18:2 fatty acid (Rioux et al., 2013; Garcia et al., 2017, 2018). Besides, TVA may be converted to the trans-13 C20:1 thanks to an elongation step (Rioux et al., 2013). Last but not least, our research group recently gave formal evidence of the peroxisomal $\beta$-oxidation of dietary TVA yielding TPA (Guillocheau et al., 2019).

As great attention was paid to CLAs isomers - including RMA - in the past decades, the metabolism of RMA in humans was extensively investigated. It is here the opportunity to remind what kind of fatty acids can arise from RMA in humans (Fig. 2). Because RMA has a conjugated double bond system, all the fatty acids that metabolically arise from it will have such a system as well. The main characterized pathway in rodents starting from RMA consists first in a $\Delta 6$-desaturation step (conjugated cis-6, cis-9, trans-11 C18:3 fatty acid), second in an elongation step (conjugated cis-8, cis-11, trans-13 C20:3 fatty acid), and third in a probably $\Delta 5$-desaturation step 


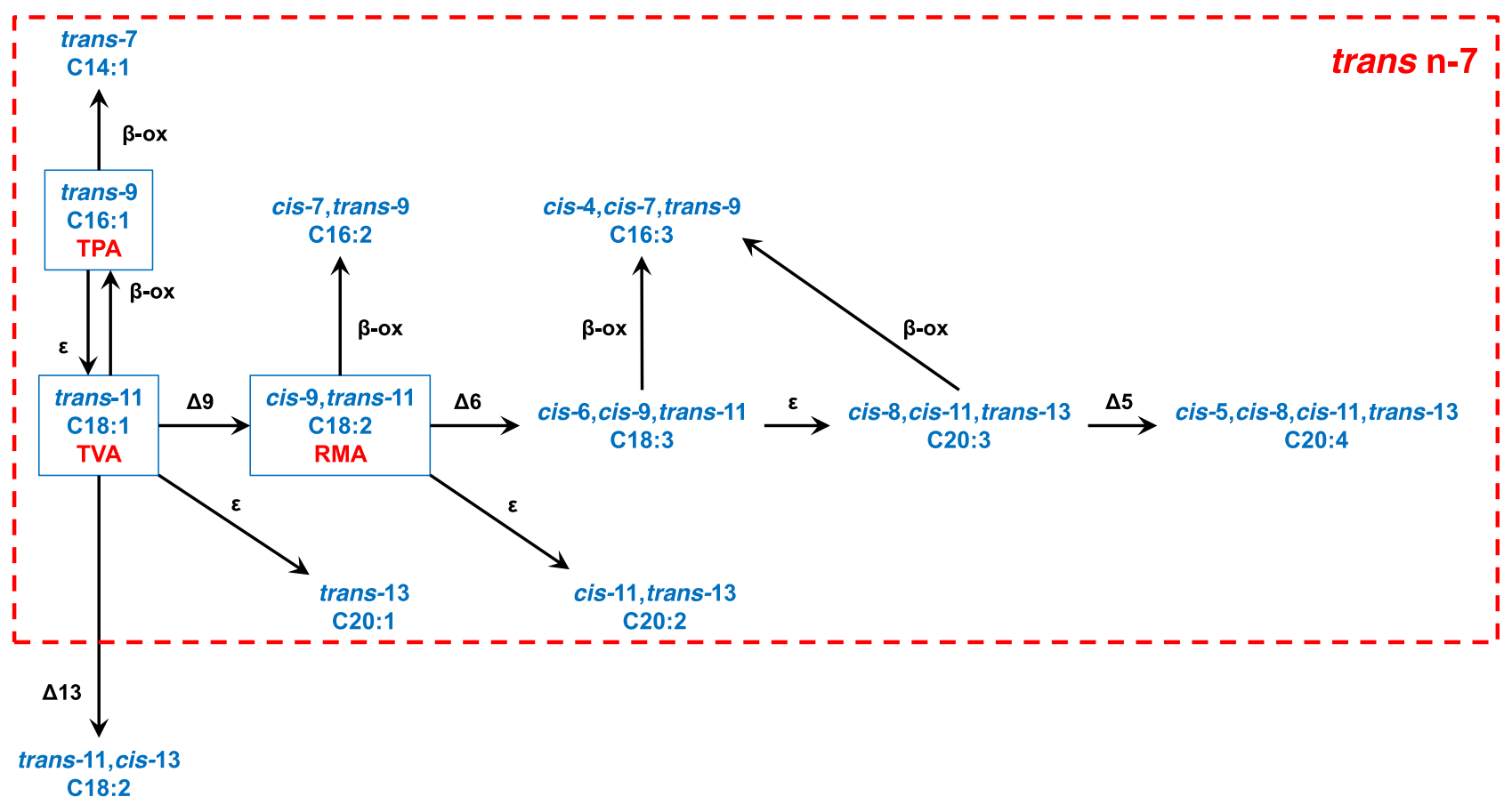

Fig. 2. Metabolic connections between trans-palmitoleic acid, trans-vaccenic acid and rumenic acid in humans. Abbreviations: RMA: rumenic acid; TPA: trans-palmitoleic acid; TVA: trans-vaccenic acid. Symbols: $\beta$-ox: peroxisomal $\beta$-oxidation; $\Delta$ : desaturation; $\varepsilon$ : elongation.

(conjugated cis-5, cis-8, cis-11, trans-13 C20:4 fatty acid) (Sébédio et al., 1997; Banni, 2002; Berdeaux et al., 2002; Banni et al., 2004a, b). Apart from this pathway, RMA is likely to be elongated and converted to the conjugated cis-11, trans13 C20:2 fatty acid. Of note, several studies pointed out conjugated $\mathrm{C} 16: 2$ and $\mathrm{C} 16: 3$ fatty acids probably arising from peroxisomal $\beta$-oxidation of RMA and its derivatives (Sébédio et al., 2001; Sergiel et al., 2001; Banni, 2002; Banni et al., $2004 a, b)$. It is worth underlining that there is no study so far that investigated the physiological effects of all these fatty acids derived from RMA.

\section{Are all dietary natural trans fatty acids bioactive?}

As said above, TPA, TVA and RMA are fatty acids of interest in human nutrition as many studies about them were carried out. Given the metabolic connections that exist between the three of these dietary natural trans fatty acids in humans, we cannot help asking a tricky question: when consuming a ruminant-derived product, are all dietary natural trans fatty acids bioactive once incorporated in humans? Following the numerous randomized control trials carried out with dairy fat or natural trans-fatty acids enriched dairy fat, RMA has very often been considered responsible for the nutritional benefits. Presumably, this has to do with its belonging to the CLA family. It is actually impossible to conclude from all these studies which natural trans fatty acid is biologically active.

As regards to TPA, it should be underlined that the epidemiological link between circulating levels of TPA and lower risk of type 2 diabetes remained significant after adjustment on circulating levels of TVA (Mozaffarian et al., 2010; Yakoob et al., 2016). Thus, these findings strongly suggest that dietary TPA possesses physiological effects that are independent of those exerted by TVA. On the other hand, the physiological impacts of trans-7 $\mathrm{C} 14: 1$ are totally unknown. Beyond, it is not known if TPA acts by itself or through metabolites other than fatty acids (e.g., oxygenated mediators).

Can TVA act independently of other natural trans fatty acids? Putting TPA apart, according to the prevailing view TVA is only the precursor of RMA thanks to its $\Delta 9$ desaturation. In other words, TVA would exert its benefits only because it can be converted to RMA, which belongs to the CLA family. One should keep in mind that TVA was proposed as a ligand of PPAR- $\alpha$ and PPAR- $\gamma$, just like RMA. In strong agreement with this idea, one remarkable study demonstrated that TVA and RMA had similar but independent anti-inflammatory effects on human peripheral blood mononuclear cells; both anti-inflammatory impacts relied on the same mechanism (Jaudszus et al., 2012). For the first time, TVA and RMA are suggested to share some physiological effects but behave independently of each other.

Even if RMA was described as a ligand of PPAR- $\alpha$ and PPAR- $\gamma$, the many fatty acids arising from RMA through elongation, peroxisomal $\beta$-oxidation and desaturation pathways should not be forgotten (Fig. 2). To the best of our knowledge, there is so far no existing work investigating the physiological effects of this distinct family of PUFAs. Because all these fatty acids were detected whenever RMA was supplemented through diet (Piras et al., 2015; Murru et al., 2018), one cannot conclude that RMA is solely responsible for any noticed benefits. 


\section{Conclusion: defining the n-7 trans fatty acid family, and opening up new research hypotheses}

For decades, it has been all about natural trans fatty acids $v s$. industrial ones as regards to the risk of cardiovascular diseases: for all these fatty acids, a negative connotation has remained. Meanwhile, CLA isomers have always been considered as beneficial fatty acids and distinguished from trans fatty acids, leading to a positive connotation.

In this review, we summed up the scientific knowledge about natural trans fatty acids which mainly consist of TPA, TVA and RMA. Because it is now recognized that current intakes of natural trans fatty acids are neutral towards cardiovascular outcomes, we wished to go beyond the cardiovascular level by emphasizing overlooked results dealing with inflammation, type 2 diabetes and obesity. We also highlighted that natural trans fatty acids share biochemical features (i.e., a n-7 double bond) and physiological impacts. For the first time, results about dietary TPA, dietary TVA and dietary RMA have been put in relationship, strengthening the conclusions about physiological impacts of dietary natural trans fatty acids.

According to the prevailing view, RMA should be the only fatty acid exerting benefits on human health. Yet, at the present time, there is no evidence of RMA being more beneficial than TVA or TPA. From this point of view, epidemiological associations linking TPA to a lower risk of type 2 diabetes independently of both TVA and RMA is a breakthrough in the field of dietary trans fatty acids. For the first time, a trans mono-unsaturated fatty acid is associated with health benefits in humans and with a positive connotation. Such results debunk the traditional distinction between CLA isomers and trans fatty acids: the former would exert benefits contrary to the latter.

Rather, the location of the last double bond (starting from the first carbon) is crucial when it comes to the relation between the biochemistry of dietary fatty acids and nutritional impacts. A well-known example is the difference between $n-6$ and n-3 polyunsaturated fatty acids. Presumably, this holds true for dietary trans fatty acids as well. Fascinatingly, TPA, TVA, RMA and all its derivatives share their last trans double bond in the n-7th position. Both dietary TVA and RMA have been proposed as powerful ligands of PPAR- $\alpha$ and PPAR- $\gamma$ to explain their health benefits, which are very close to those presumed for dietary TPA. We propose to define the trans n-7 fatty acids, corresponding to the natural trans fatty acids and gathering TPA, TVA, RMA and all its derivatives. We also hypothesize that all these fatty acids target PPAR- $\alpha$ and PPAR$\gamma$, explaining their protective impact towards inflammation, type 2 diabetes and obesity.

Further research is needed to confirm such interesting hypothesis, including epidemiological data but especially supplementation studies. Defining the n-7 trans fatty acid family triggers to several scientific questions. First, even if natural trans fatty acids share some common features, we cannot rule out the existence of specific physiological impacts. Second, it is still unknown whether these fatty acids act directly or through lipid mediators, like n-6 and n-3 polyunsaturated fatty acids. Third, how about comparing n-7 trans and n-7 cis fatty acids? Not only was cis-palmitoleic acid (cis-C16:1 n-7) described in 2008 as a lipokine (Cao et al., 2008), but Mozaffarian et al. also assumed that cispalmitoleic and its trans isomer (i.e., TPA) act the same way (Mozaffarian et al., 2010). Finally, one should also keep in mind the ability for gut microbiota to synthesize TVA and RMA from dietary LA and ALA (Druart et al., 2013), just like what happens in ruminants. Thus, trans fatty acids might be intermediate molecules by which gut microbiota exerts benefits on humans.

\section{Funding}

The present research was financially supported by the French Dairy Interbranch Organization (CNIEL) (PALMITO project) and the Lipids and Nutrition Group (GLN).

Acknowledgements. EG acknowledges a CIFRE (Industrial Agreement of Training through Research) $\mathrm{PhD}$ fellowship from both the French Dairy Interbranch Organization (CNIEL) and the National Association for Research and Technology (ANRT) (CIFRE fellowship number 2015/1195).

Conflicts of interest. EG is employed by the French Dairy Interbranch Organization (CNIEL).

\section{References}

AFSSA. 2005. Risques et bénéfices pour la santé des acides gras trans apportés par les aliments-Recommandations. DOI: 10.1051/ mnut/2008444149.

Aldai N, Dugan MER, Rolland DC, Kramer JKG. 2009. Survey of the fatty acid composition of Canadian beef: Backfat and longissimus lumborum muscle. Can J Anim Sci 89(3): 315-329. DOI: 10.4141/CJAS08126.

Aldai N, Dugan MER, Kramer JKG. 2010. Can the trans-18:1 and conjugated linoleic acid profiles in retail ground beef be healthier than steak? J Food Compost Anal 23(4): 326-332. DOI: 10.1016/ j.jfca.2010.01.004.

Banni S. 2002. Conjugated linoleic acid metabolism. Curr Opin Lipidol 13: 261-266.

Banni S, Petroni A, Blasevich M, et al. 2004a. Detection of conjugated C16 PUFAs in rat tissues as possible partial betaoxidation products of naturally occurring conjugated linoleic acid and its metabolites. Biochim Biophys Acta Mol Cell Biol Lipids 1682(1-3): 120-127. DOI: 10.1016/j.bbalip.2004.03.003.

Banni S, Petroni A, Blasevich M, et al. 2004b. Conjugated linoleic acids (CLA) as precursors of a distinct family of PUFA. Lipid 39 (11): 1143-1146. DOI: 10.1007/s11745-004-1341-0.

Berdeaux O, Gnädig S, Chardigny J-M, Loreau O, Noël J-P, Sébédio J-L. 2002. In vitro desaturation and elongation of rumenic acid by rat liver microsomes. Lipids 37(11): 1039-1045. DOI: 10.1007/ s11745-002-0998-8.

Blewett HJ, Gerdung CA, Ruth MR, Proctor SD, Field CJ. 2009. Vaccenic acid favourably alters immune function in obese JCR: LA-cp rats. Br J Nutr 102(04): 526. DOI: 10.1017/ S0007114509231722.

Bravo-Lamas L, Barron LJR, Kramer JKG, Etaio I, Aldai N. 2016. Characterization of the fatty acid composition of lamb commercially available in northern Spain: Emphasis on the trans-18:1 and CLA content and profile. Meat Sci 117: 108-116. DOI: $10.1016 /$ j.meatsci.2016.02.043. 
Cao H, Gerhold K, Mayers JR, Wiest MM, Watkins SM, Hotamisligil GS. 2008. Identification of a lipokine, a lipid hormone linking adipose tissue to systemic metabolism. Cell 134(6): 933-944. DOI: 10.1016/j.cell.2008.07.048.

Cimen I, Yildirim Z, Dogan AE, et al. 2019. Double bond configuration of palmitoleate is critical for atheroprotection. Mol Metab 28: 58-72. DOI: 10.1016/j.molmet.2019.08.004.

Clément L, Poirier H, Niot I, et al. 2002. Dietary trans-10, cis-12 conjugated linoleic acid induces hyperinsulinemia and fatty liver in the mouse. J Lipid Res 43(9): 1400-1409. DOI: 10.1194/j1r. M20008-JLR200.

CODEX. 1985. CODEX Alimentarius (CODEX) Guidelines on Nutrition Labeling CAC/GL 2-1985 as Last Amended 2013.

Da Silva MS, Julien P, Couture P, Lemieux S, Vohl M-C, Rudkowska I. 2014. Associations between dairy intake and metabolic risk parameters in a healthy French-Canadian population. Appl Physiol Nutr Metab 39(12): 1323-1331. DOI: 10.1139/apnm2014-0154.

Da Silva MS, Julien P, Bilodeau J-F, Barbier O, Rudkowska I. 2017. Trans fatty acids suppress TNF $\alpha$-induced inflammatory gene expression in endothelial (HUVEC) and hepatocellular carcinoma (HepG2) cells. Lipids. DOI: 10.1007/s11745-017-4243-4.

de Oliveira Otto MC, Nettleton JA, Lemaitre RN, et al. 2013. Biomarkers of dairy fatty acids and risk of cardiovascular disease in the Multi-Ethnic Study of Atherosclerosis. J Am Heart Assoc 2 (4): e000092. DOI: 10.1161/JAHA.113.000092.

de Souza RJ, Mente A, Maroleanu A, et al. 2015. Intake of saturated and trans unsaturated fatty acids and risk of all cause mortality, cardiovascular disease, and type 2 diabetes: Systematic review and meta-analysis of observational studies. BMJ 351: 1-16. DOI: 10.1136/bmj.h3978.

Destaillats F, Wolff RL, Precht D, Molkentin J. 2000. Study of individual trans- and cis-16:1 isomers in cow, goat, and ewe cheese fats by gas-liquid chromatography with emphasis on the trans- $\Delta 3$ isomer. Lipids 35(9): 1027-1032. DOI: 10.1007/ s11745-000-0614-y.

Druart C, Neyrinck AM, Dewulf EM, et al. 2013. Implication of fermentable carbohydrates targeting the gut microbiota on conjugated linoleic acid production in high-fat-fed mice. $\mathrm{Br} J$ Nutr 110(6): 998-1011. DOI: 10.1017/S0007114513000123.

Duffy PE, Quinn SM, Roche HM, Evans P. 2006. Synthesis of transvaccenic acid and cis-9-trans-11-conjugated linoleic acid. Tetrahedron 62(20): 4838-4843. DOI: 10.1016/j.tet.2006.03.006.

EFSA. 2004. Opinion of the Scientific Panel on Dietetic Products, Nutrition and Allergies on a request from the Commission related to the presence of trans fatty acids in foods and the effect on human health of the consumption of trans fatty acids. EFSA J 2(8), 81: 1-49. DOI: 10.2903/j.efsa.2004.81.

FDA. 2003. Food Labeling: Trans Fatty Acids in Nutrition Labeling, Nutrient Content Claims, and Health Claims. Fed Reg 68(133): 41433-41506.

Gaita M, Marano A, Della-Gatta A, et al. 2014. c9, t11-conjugated linoleic acid ameliorates steatosis by modulating mitochondrial uncoupling and Nrf2 pathway. J Lipid Res 55(5): 837-849. DOI: 10.1194/jlr.m044032.

Garcia C, Duby C, Catheline D, et al. 2017. Synthesis of the suspected trans- 11 , cis- 13 conjugated linoleic acid isomer in ruminant mammary tissue by FADS3-catalyzed $\Delta 13$-desaturation of vaccenic acid. J Dairy Sci 100(1): 783-796. DOI: 10.3168/ jds.2016-11455.

Garcia C, Guillocheau E, Richard L, et al. 2018. Conversion of dietary trans-vaccenic acid to trans 11 , cis13-conjugated linoleic acid in the rat lactating mammary gland by fatty acid desaturase 3-catalyzed methyl-end $\Delta 13$-desaturation. Biochem Biophys Res Commun 505(2): 385-391. DOI: 10.1016/j.bbrc.2018.09.132.

Gebauer SK, Destaillats F, Mouloungui Z, et al. 2011. Effect of trans fatty acid isomers from ruminant sources on risk factors of cardiovascular disease: Study design and rationale. Contemp Clin Trials 32(4): 569-576. DOI: 10.1016/j.cct.2011.03.012.

Gebauer SK, Destaillats F, Dionisi F, Krauss RM, Baer DJ. 2015. Vaccenic acid and trans fatty acid isomers from partially hydrogenated oil both adversely affect LDL cholesterol: A double-blind, randomized controlled trial. Am J Clini Nutr 102(6): 1339-1346. DOI: 10.3945/ajcn.115.116129.

Gruffat D, De La Torre A, Chardigny J-M, Durand D, Loreau O, Bauchart D. 2005. Vaccenic acid metabolism in the liver of rat and bovine. Lipids 40(3): 295-301. DOI: 10.1007/ s11745-005-1385-1.

Guillocheau E, Penhoat C, Godet A, Catheline D, Legrand P, Rioux V. 2018. Dairy products as main dietary sources of trans-palmitoleic and trans-vaccenic acid in France. IDF-World Dairy Summit 2018. DOI: $10.13140 /$ RG.2.2.15586.17607.

Guillocheau E, Garcia C, Drouin G, et al. 2019. Retroconversion of dietary trans-vaccenic (trans-C18:1 n-7) acid to trans-palmitoleic acid (trans-C16:1 n-7): Proof of concept and quantification in both cultured rat hepatocytes and pregnant rats. J Nutr Biochem 63: 19-26. DOI: 10.1016/j.jnutbio.2018.09.010.

Imamura F, Fretts AM, Marklund M, et al. 2018. Fatty acid biomarkers of dairy fat consumption and incidence of type 2 diabetes: A pooled analysis of prospective cohort studies. PLoS Med 15(10). DOI: 10.1371/journal.pmed.1002670.

Jacome-Sosa MM, Borthwick F, Mangat R, et al. 2014. Diets enriched in trans-11 vaccenic acid alleviate ectopic lipid accumulation in a rat model of NAFLD and metabolic syndrome. J Nutr Biochem 25 (7): 692-701. DOI: 10.1016/j.jnutbio.2014.02.011.

Jaudszus A, Foerster M, Kroegel C, Wolf I, Jahreis G. 2005. Cis-9, Trans-11-CLA exerts anti-inflammatory effects in human bronchial epithelial cells and eosinophils: Comparison to Trans-10, Cis-12-CLA and to linoleic acid. Biochim Biophys Acta Mol Cell Biol Lipids 1737(2-3): 111-118. DOI: 10.1016/j. bbalip.2005.11.001.

Jaudszus A, Krokowski M, Möckel P, et al. 2008. Cis-9, trans-11conjugated linoleic acid inhibits allergic sensitization and airway inflammation via a PPAR $\gamma$-related mechanism in mice. JNutr 138 (7): 1336-1342. DOI: 10.1093/jn/138.7.1336.

Jaudszus A, Jahreis G, Schlörmann W, et al. 2012. Vaccenic acidmediated reduction in cytokine production is independent of $\mathrm{c} 9$, t11-CLA in human peripheral blood mononuclear cells. Biochim Biophys Acta Mol Cell Biol Lipids 1821(10): 1316-1322. DOI: 10.1016/j.bbalip.2012.06.010.

Kraft J, Hanske L, Mo P, Kramer JKG, Jahreis G. 2006. The Conversion Efficiency of trans-11 and trans-12 18:1 by $\Delta 9$ desaturation differs in rats. $J$ Nutr (January): 1209-1214. DOI: 10.1093/jn/136.5.1209.

Kraft J, Jetton T, Satish B, Gupta D. 2015. Dairy-derived bioactive fatty acids improve pancreatic $\beta$-cell function. FASEB $J 29$ (1_supplement): 608-625.

Kuhnt K, Kraft J, Moeckel P, Jahreis G. 2006. Trans-11-18:1 is effectively $\Delta$ 9-desaturated compared with trans-12-18:1 in humans. Br J Nutr 95(4): 752-761. DOI: 10.1079/BJN20051680.

Kuhnt K, Baehr M, Rohrer C, Jahreis G. 2011. Trans fatty acid isomers and the trans-9/trans-11 index in fat containing foods. Eur J Lipid Sci Technol 113(10): 1281-1292. DOI: 10.1002/ ej1t.201100037.

Loscher CE, Draper E, Leavy O, Kelleher D, Mills KHG, Roche HM. 2014. Conjugated linoleic acid suppresses NF-B activation and 
IL-12 production in dendritic cells through ERK-mediated IL-10 induction. J Immunol 175(8): 4990-4998. DOI: 10.4049/ jimmunol.175.8.4990.

Mendis S, Cruz-Hernandez C, Ratnayake WMN. 2008. Fatty acid profile of Canadian dairy products with special attention to the trans-octadecenoic acid and conjugated linoleic acid isomers. $J$ AOAC Int 91(4): 811-819.

Micha R, King IB, Lemaitre, RN, et al. 2010. Food sources of individual plasma phospholipid trans fatty acid isomers: The Cardiovascular Health Study. Am J Clin Nutr 91(4): 883-893. DOI: $10.3945 /$ ajcn.2009.28877.

Mohankumar SK, Hanke D, Siemens L, et al. 2013. Dietary supplementation of trans-11-vaccenic acid reduces adipocyte size but neither aggravates nor attenuates obesity-mediated metabolic abnormalities in fa/fa Zucker rats. Br J Nutr 109(9): 1628-1636. DOI: $10.1017 / \mathrm{S} 000711451200339 \mathrm{X}$.

Moloney F, Toomey S, Noone E, et al. 2007. Antidiabetic effects of cis-9, trans-11-conjugated linoleic acid may be mediated via antiinflammatory effects in white adipose tissue. Diabetes 56(3): 574-582. DOI: 10.2337/db06-0384.

Mosley EE, McGuire MK, Williams JE, McGuire MA. 2006. Cis-9, Trans-11 conjugated linoleic acid is synthesized directly from vaccenic acid in lactating women. J Nutr 136(9): 2297-2301. DOI: $10.1093 /$ jn/136.9.2297.

Mouloungui Z, Candy L. 2009. Chemical synthesis of monounsaturated trans fatty acids. In: Destaillats F, Sébédio J-L, Dionisi F, Chardigny J-M, eds. Trans fatty acids in human nutrition. Second, pp. 77-103. DOI: 10.1533/9780857097873.77.

Moya-Camarena SY, Vanden Heuvel JP, Blanchard SG, Leesnitzer LA, Belury MA. 1999. Conjugated linoleic acid is a potent naturally occurring ligand and activator of PPAR $\alpha$. J Lipid Res 40 (8): 1426-1433.

Mozaffarian D, Cao H, King IB, et al. 2010. Trans-palmitoleic acid, metabolic risk factors, and new-onset diabetes in U.S. adults: A cohort study. Ann Intern Med 153(12): 790-799. DOI: 10.7326/ 0003-4819-153-12-201012210-00005.

Mozaffarian D, de Oliveira Otto MC, Lemaitre RN, et al. 2013. Transpalmitoleic acid, other dairy fat biomarkers, and incident diabetes: The Multi-Ethnic Study of Atherosclerosis (MESA). Am J Clin Nutr 97(4): 854-861. DOI: 10.3945/ajcn.112.045468.

Mozaffarian D, Cao H, Hotamisligil GS. 2014. Patent No. Patent US 8, 889, 739 B2. DOI: 10.1016/j.(73).

Murru E, Carta G, Cordeddu L, et al. 2018. Dietary conjugated linoleic acid-enriched cheeses influence the levels of circulating n-3 highly unsaturated fatty acids in humans. Int J Mol Sci 19(6): 1730. DOI: $10.3390 /$ ijms19061730.

Nestel PJ, Straznicky N, Mellett NA, et al. 2014. Specific plasma lipid classes and phospholipid fatty acids indicative of dairy food consumption associate with insulin sensitivity. Am J Clin Nutr 99: 46-53. DOI: 10.3945/ajcn.113.071712.INTRODUCTION.

Piras A, Carta G, Murru E, et al. 2015. Effects of dietary CLA on n-3 HUFA score and $\mathrm{N}$-acylethanolamides biosynthesis in the liver of obese Zucker rats. Prostaglandins Leukot Essent Fatty Acids 98: 15-19. DOI: 10.1016/j.plefa.2015.04.004.

Pranger IG, Muskiet FAJ, Kema IP, Singh-Povel C, Bakker SJL. 2019. Potential biomarkers for fat from dairy and fish and their association with cardiovascular risk factors: Cross-sectional data from the LifeLines Biobank and Cohort Study. Nutrients 11(5): 1099. DOI: 10.3390/nu11051099.

Precht D, Molkentin J. 1996. Rapid analysis of the isomers of transoctadecenoic acid in milk fat. Int Dairy J 6(8-9): 791-809. DOI: 10.1016/0958-6946(96)00004-0.
Precht D, Molkentin J. 2000a. Recent trends in the fatty acid composition of German sunflower margarines, shortenings and cooking fats with emphasis on individual C16:1, C18:1, C18:2, C18:3 and C20:1 trans isomers. Nahrung 16(4): 0-6. DOI: 10.1002/ 1521-3803(20000701)44:4<222::AID-FOOD222>3.0.CO;2-9.

Precht D, Molkentin, J. 2000b. Trans unsaturated fatty acids in bovine milk fat and dairy products. Eur J Lipid Sci Technol 102(10): 635640. DOI: 10.1002/1438-9312(200010)102:10<635::AIDEJLT635>3.0.CO;2-A.

Reynolds CM, Loscher CE, Moloney AP, Roche HM. 2008. Cis-9, trans-11-conjugated linoleic acid but not its precursor transvaccenic acid attenuate inflammatory markers in the human colonic epithelial cell line Caco-2. Br J Nutr 100(1): 13-17. DOI: 10.1017/S0007114508894329.

Rioux V, Pédrono F, Blanchard H, et al. 2013. Trans-vaccenate is $\Delta 13$-desaturated by FADS3 in rodents. J Lipid Res 54(12): 3438 3452. DOI: $10.1194 / \mathrm{jl}$.M042572.

Roche HM., Noone E, Sewter C, et al. 2002. Isomer-dependent metabolic effects of conjugated linoleic acid: Insights from molecular markers sterol regulatory element-binding protein-1c and LXR $\alpha$. Diabetes 51(7): 2037-2044. DOI: 10.2337/diabe tes.51.7.2037.

Santaren ID, Watkins SM, Liese AD, et al. 2014. Serum pentadecanoic acid (15:0), a short-term marker of dairy food intake, is inversely associated with incident type 2 diabetes and its underlying disorders. Am Clin Nutr 100(6): 1532-1540. DOI: 10.3945/ajcn.114.092544.

Santora JE, Palmquist DL, Roehrig KL. 2000. Trans-vaccenic acid is desaturated to conjugated linoleic acid in mice. $J$ Nutr 130(2): 208-215. DOI: 10.1093/jn/130.2.208.

Sébédio J-L, Juanéda P, Dobson G, et al. 1997. Metabolites of conjugated isomers of linoleic acid (CLA) in the rat. Biochim Biophys Acta Lipids Lipid Metab 1345(1): 5-10. DOI: 10.1016/ S0005-2760(97)00015-5.

Sébédio J-L, Angioni E, Chardigny J-M, Grégoire S, Juanéda P, Berdeaux O. 2001. The effect of conjugated linoleic acid isomers on fatty acid profiles of liver and adipose tissues and their conversion to isomers of $16: 2$ and $18: 3$ conjugated fatty acids in rats. Lipids 36(6): 575-582. DOI: 10.1007/s11745-001-0759-8.

Sehat N, Kramer JKG, Mossoba MM, et al. 1998. Identification of conjugated linoleic acid isomers in cheese by gas chromatography, silver ion high performance liquid chromatography and mass spectral reconstructed ion profiles. Comparison of chromatographic elution sequences. Lipids 33(10): 963-971. DOI: 10.1007/s11745-998-0293-8.

Sergiel JP, Chardigny J-M, Sébédio J-L, et al. 2001. $\beta$-oxidation of conjugated linoleic acid isomers and linoleic acid in rats. Lipids 36(12): 1327-1329.

Sun Q, Ma J, Campos H, Hu FB. 2007. Plasma and erythrocyte biomarkers of dairy fat intake and risk of ischemic heart disease. Am J Clin Nutr 86(4): 929-937. DOI: 10.1093/ajcn/86.4.929.

Tremblay BL, Rudkowska I. 2017. Nutrigenomic point of view on effects and mechanisms of action of ruminant trans fatty acids on insulin resistance and type 2 diabetes. Nutr Rev 75(3): 214-223. DOI: 10.1093/nutrit/nuw066.

Turpeinen AM, Mutanen M, Aro A, et al. 2002. Bioconversion of vaccenic acid to conjugated linoleic acid in humans. Am J Clin Nutr 76(3): 504-510. DOI: 10.1093/ajen/76.3.504.

Turpeinen AM, Ylönen N, von Willebrand E, Basu S, Aro A. 2008. Immunological and metabolic effects of cis-9, trans-11-conjugated linoleic acid in subjects with birch pollen allergy. Br J Nutr 100 (01): 112-119. DOI: 10.1017/s0007114507886326. 
Wang Y, Lu J, Ruth MR, et al. 2008. Trans-11 vaccenic acid dietary supplementation induces hypolipidemic effects in JCR: LA-cp Rats. J Nutr 138(11): 2117-2122. DOI: 10.3945/ jn.108.091009.

Wang Y, Jacome-Sosa MM, Ruth MR, et al. 2012. The intestinal bioavailability of vaccenic acid and activation of peroxisome proliferator-activated receptor- $\alpha$ and $-\gamma$ in a rodent model of dyslipidemia and the metabolic syndrome. Mol Nutr Food Res 56 (8): 1234-1246. DOI: 10.1002/mnfr.201100517.

Wolff RL, Combe NA, Destaillats F, et al. 2000. Follow-up of the $\Delta 4$ to $\Delta 16$ trans-18:1 isomer profile and content in French processed foods containing partially hydrogenated vegetable oils during the period 1995-1999. Analytical and nutritional implications. Lipids 35(8): 815-825. DOI: 10.1007/S11745-000-0590-2.

Yakoob MY, Shi P, Willett WC, et al. 2016. Circulating biomarkers of dairy fat and risk of incident diabetes mellitus among US men and women in two large prospective cohorts. Circulation 133(17). DOI: 10.1161/CIRCULATIONAHA.115.018410.

Yang M, Cook ME. 2003. Dietary conjugated linoleic acid decreased cachexia, macrophage tumor necrosis factor- $\alpha$ production, and modifies splenocyte cytokines production. Exp Bio Med 228(1): 51-58. DOI: 10.1177/153537020322800107.

Cite this article as: Guillocheau E, Legrand P, Rioux V. 2019. Benefits of natural dietary trans fatty acids towards inflammation, obesity and type 2 diabetes: defining the n-7 trans fatty acid family. OCL 26: 46. 